\title{
Biosynthesis of Gold Nanoparticles by Human Microbiota from Healthy Skins
}

Pooja Deshpande ${ }^{1 *}$, Sharvari Gaidhani ${ }^{2}$, Hitendra $\mathbf{M}^{3}$, Yogesh Shouche ${ }^{3}$, Narhe $\mathbf{R}^{4}$, Richa Singh ${ }^{1}$, Sweety Wadhwani ${ }^{1}$, Utkarsha Shedbalkar ${ }^{1}$, Dhanjay Gond ${ }^{2}$ and Balu Ananda Chopade ${ }^{1,2}$

${ }^{1}$ Genetic and Molecular Biology Laboratory, Department of Microbiology, University of Pune, Pune, Maharashtra, India

${ }^{2}$ Institute of Bioinformatics and Biotechnology, University of Pune, Pune, Maharashtra, India

${ }^{3}$ National Center for Cell Science, Pune, Maharashtra, India

${ }^{4}$ Department of Physics, University of Pune, Pune, Maharashtra, India

\begin{abstract}
High moisture content of human allows prevalence of microbial flora as commensals. The present study aimed at isolation, purification, identification of human micro flora found in anticubital fosse in Indian adult individuals and their ability to produce metal nanoparticles. Swabs were collected from 80 healthy individuals consisting of $50 \%$ of male. Preliminary morphological identification of nine isolates (HACF 1, $4-9,11$ ) was performed for the colonies growing on specific isolation medium. Isolates were identified by API 32 GN system and 16S r RNA gene sequencing. Providencia spp. HACF 11 exhibited the ability to produce cell bound gold nanoparticles by producing a 550nm in UVVisible spectroscopy. It was further confirmed by TEM and SEM analysis. Temperature was found to exhibit profound effect on synthesis with increasing monodispersity producing spherical nanoparticles. With increase in temperature, the time required for synthesis of gold nanoparticles reduced to $24 \mathrm{~h}$.
\end{abstract}

Keywords: Human microflora; Isolation; API 32GN system; $16 \mathrm{~S}$ rRNA gene identification; UV-Vis spectroscopy; TEM; SEM; Gold nanoparticles

\section{Introduction}

The skin is the human body's largest organ, colonized by a diverse milieu of microorganisms, most of which are harmless or even beneficial to their host [1-12]. Metagenomic analysis has revealed that Staphylococcus and Corynebacterium spp. are the most abundant organisms colonizing moist areas [13,14]. Consistent with culture data suggesting that these organisms prefer areas of high humidity. These moist sites include the umbilicus (navel), the axillary vault, the inguinal crease (side of the groin), the gluteal crease (topmost part of the fold between the buttocks), the sole of the foot, the popliteal fossa (behind the knee) and the antecubital fossa (inner elbow) [12]. Study aimed at isolation, purification and identification microbiota from anticubital fossa and its abilty to synthesize metal nanoparticles. There is an interest in the synthesis of nanomaterials because they exhibit unique physical, chemical, optical, electrical, magnetic, mechanical, thermal, dielectric, and biological properties, different from those of bulk materials, due to their distinct size- and shape-dependent characteristics [15] also the microbiota isolated is non-pathogenic and no detailed reports, yet been available on biosynthesis of gold nanoparticles from such microbiome were found. We also investigated the effect of reaction parameters on the rate of synthesis of AuNPs .

\section{Materials and Methods}

\section{Subjects}

Subjects in this study were students, faculty and employees of the University of Pune

\section{Culture sites}

Cultures were harvested from human anticubital fossa.

\section{Microbiological method}

A wet cotton swabs was used to collect bacteria from circular area of anticubital fossae [4] in sterile conditions .Samples were collected in summer and rainy season. Serial dilutions were made and culture on various cultured medias like NA, LA, C.L.E.D, AMM etc. When it was found that the quantities were not significantly different only nine isolates were secured.

\section{Characterization and identification of isolates}

Isolates were characterized for size, shape, margin, opacity, elevation, consistency, Gram nature, catalase, oxidase, capsule staining, lactose fermentation.

Isolates were identified by API $32 \mathrm{GN}$ system and $16 \mathrm{~S}$ r RNA gene sequencing and are as under Staphylococcus saprophyticus, Micrococcus luteus, Staphylococcus homnis, Staphylococcus gallinaium, Providencia sp..

\section{Growth media and inoculation}

Isolates were maintained on LB agar slants (Himedia Mumbai India) agar plate/slant at $4^{\circ} \mathrm{C}$ and as glycerol stocks at $-80^{\circ} \mathrm{C}$. For inoculum preparation, a loopful of the culture was inoculated into $100 \mathrm{~mL}$ sterile Luria Bertani broth and incubated at $30^{\circ} \mathrm{C} / 200 \mathrm{rpm}$ for 24 hours to 7 . A single colony of each of the respective isolates was inoculated in each of the respective flasks. The conical flasks were then kept on shaking incubator for $24 \mathrm{hrs}$ at $37^{\circ} \mathrm{C}$.

Screening of the isolates for nanoparticles synthesis of nanoparticles synthesis

All the identified isolates were screened for nanoparticles synthesis

*Corresponding author: Pooja Deshpande, Genetic and Molecular Biology Laboratory, Department of Microbiology, University of Pune, Pune, Maharashtra, India, Tel: 020-25601377; Fax: 91-20-25690643; E-mail: poojadeshpande10@ yahoo.com

Received May 12, 2015; Accepted May 21, 2015; Published June 04, 2015

Citation: Deshpande P, Gaidhani S, Hitendra M, Shouche Y, Narhe R, et al. (2015) Biosynthesis of Gold Nanoparticles by Human Microbiota from Healthy Skin. J Nanomed Nanotechnol 6: 300. doi: 10.4172/2157-7439.1000300

Copyright: ( 2015 Deshpande P, et al. This is an open-access article distributed under the terms of the Creative Commons Attribution License, which permits unrestricted use, distribution, and reproduction in any medium, provided the original author and source are credited. 
Citation: Deshpande P, Gaidhani S, Hitendra M, Shouche Y, Narhe R, et al. (2015) Biosynthesis of Gold Nanoparticles by Human Microbiota from Healthy Skin. J Nanomed Nanotechnol 6: 300. doi:10.4172/2157-7439.1000300

Page 2 of 3

of different metals like gold, silver, platinum, palladium and copper respectively. Only the isolate HACF-11 i.e Providencia sp showed ability to produce AuNPs. So, futher experiment was carried out with isolate HACF-11 only (Table 1).

\section{Synthesis of AuNPs and ultraviolet-visible (UV-Vis) spectra analysis}

For screening, the Isolates (optical density $[\mathrm{OD}] 600 \approx 1 \times 10^{10} \mathrm{CFU} /$ $\mathrm{mL}$ ) were suspended into sterile Milli- $\mathrm{Q}^{\circ}$ water $(\mathrm{pH} 7)$ after repeated rinses to remove the traces of media and incubated at $30^{\circ} \mathrm{C} / 200 \mathrm{rpm}$ for 72 hours. Synthesis of AuNPs was visually observed for a color change over a period of 72 hours. Reduction of $\mathrm{Au}^{+}$ions was monitored by recording the UV-Vis spectrum between 300 and $800 \mathrm{~nm}$ at regular intervals up to 168 hours on SpectraMax M5 Multi-mode Microplate Reader (Molecular Devices LLC, Sunnyvale, CA, USA). The strain giving maximum absorbance was selected. All the isolates were screened for nanoparticles synthesis for different metals and those which were positive for nanoparticles synthesis.

\section{Characterisation of AuNPs}

After 72 hours of synthesis, the sample of AuNPs was centrifuged at $14,000 \mathrm{rpm}$ for 30 minutes at room temperature. Repeated rinses were performed to remove impurities. The pellet of AgNPs was suspended in $1 \mathrm{~mL}$ sterile Milli-Q water. Samples for transmission electron microscopy (TEM) and high-resolution TEM (HR-TEM) were prepared by drop-coating the AgNPs solution on a carbon-coated copper grid and drying under infrared radiation. The analyses were performed on FEI Tecnai G ${ }^{2} 12$ BioTwin (FEI Company, Eindhoven, the Netherlands) TEM. A drop of AuNP sample was taken and dried on a glass slide for analysis under a scanning electron microscope (SEM) (JSM-6360; JEOL, Tokyo, Japan) at $20 \mathrm{kV}$ accelerating voltage.

\section{Effect of Reaction parameters on the morphology of AuNPs}

To obtain the optimized reaction parameters giving maximum synthesis of AuNPs, firstly, $\mathrm{AuNO}_{3}$ ranging from 0.1 to $5 \mathrm{mM}$ (final concentration) was added to the cell suspension and incubated at temperature from $20^{\circ} \mathrm{C}-50^{\circ} \mathrm{C}$ for $72 \mathrm{hrs}$. Synthesis failed to be initiated at lower temperatures like $20^{\circ} \mathrm{C}$ while a moderate rate of reaction was observed at $30^{\circ} \mathrm{C}$ and $40^{\circ} \mathrm{C}$. The rate of reaction was found to be maximum at $50^{\circ} \mathrm{C}$ which supported the fact that higher temperature plays a key role in enhancing the reaction rate. UV-Vis spectra and TEM analyses were carried out to study morphology with varying salt concentrations and reaction temperatures.

\section{Result and Discussion}

\section{Synthesis and characterisation of AuNPs}

A Study on the biosynthesis of AuNPs by 8 strains isolated from human skin microbiota was carried out. All of the strains showed positive results for the Synthesis of AuNPs. But Providencia sp was selected for further studies because it gave synthesis in minimum time. Visual observation of cells incubated with $\mathrm{HAuCl}_{4} \cdot \mathrm{H}_{2} \mathrm{O}$ showed a color change from colorless to purple to dark violet, clearly indicating the formation of AuNPs (Figure 1). In the UV-Vis spectrum, a single, strong, and broad peak was observed at $500 \mathrm{~nm}$, confirming the synthesis of AuNPs using isolates).

As temperature increases the rate of synthesis of nanoparticles also get increased revels that at higher temperature the synthesis is rapid. Hence temperature was optimized to $50^{\circ} \mathrm{C}$ (Figures 2 and 3).

\section{Conclusion}

This is the first report on biosynthesis of AuNPs by using Providencia $s p$, an human microbiome isolate from anticubital fosse, which was optimized for reaction parameters. Futher studies on the applications of these gold nanoparticles is been carried.

\section{Acknowledgment}

\begin{tabular}{|c|c|c|c|c|c|c|c|c|c|}
\hline Metals & HACF-1 & HACF-2 & HACF-3 & HACF-4 & HACF-6 & HACF-7 & HACF-8 & HACF-9 & HACF-11 \\
\hline $\mathrm{Au}$ & - & - & - & - & - & - & - & - & + \\
\hline $\mathrm{Ag}$ & - & - & - & - & - & - & - & - & - \\
\hline $\mathrm{Pt}$ & - & - & - & - & - & - & - & - & - \\
\hline $\mathrm{Pd}$ & - & - & - & - & - & - & - & - & -- \\
\hline $\mathrm{Cu}$ & - & - & - & - & - & - & - & - & - \\
\hline
\end{tabular}

$\mathrm{i}[-]=$ negative $\mathrm{ii}=[+]$ positive

Table 1: Screening of the isolates for nanoparticles synthesis of nanoparticles synthesis.

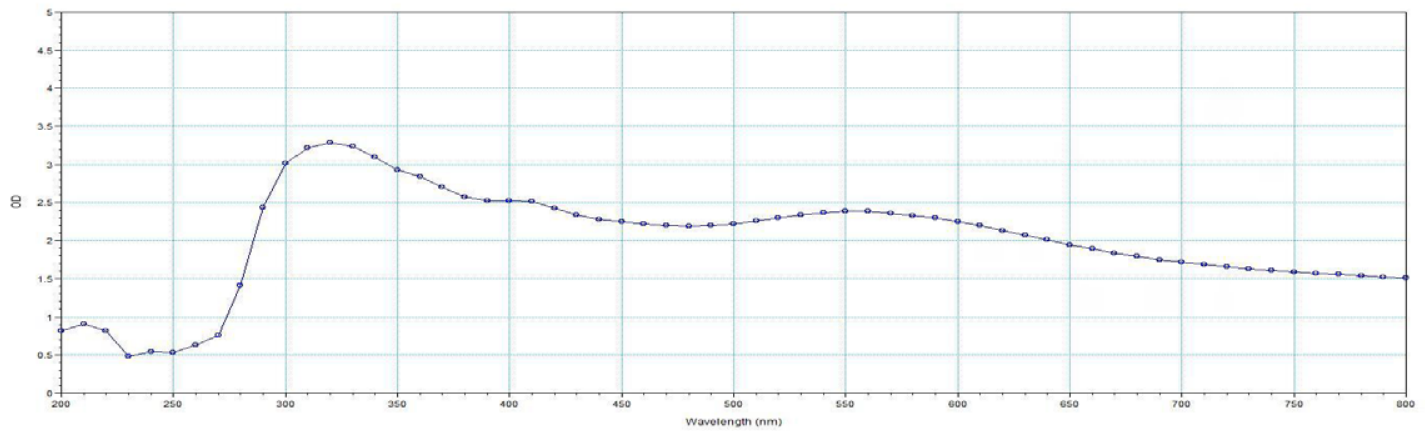

Figure 1: Synthesis of AuNPs using isolates. 
Citation: Deshpande P, Gaidhani S, Hitendra M, Shouche Y, Narhe R, et al. (2015) Biosynthesis of Gold Nanoparticles by Human Microbiota from Healthy Skin. J Nanomed Nanotechnol 6: 300. doi:10.4172/2157-7439.1000300

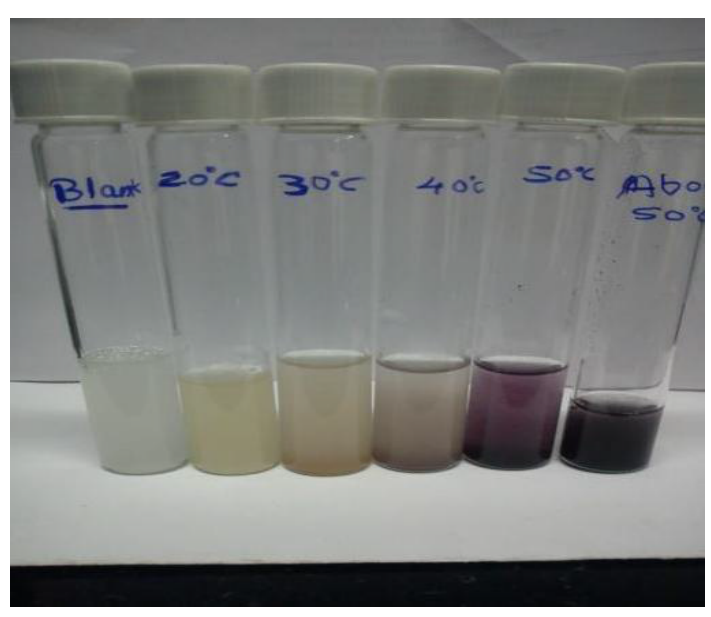

Figure 2: Color change at various reaction temperatures.
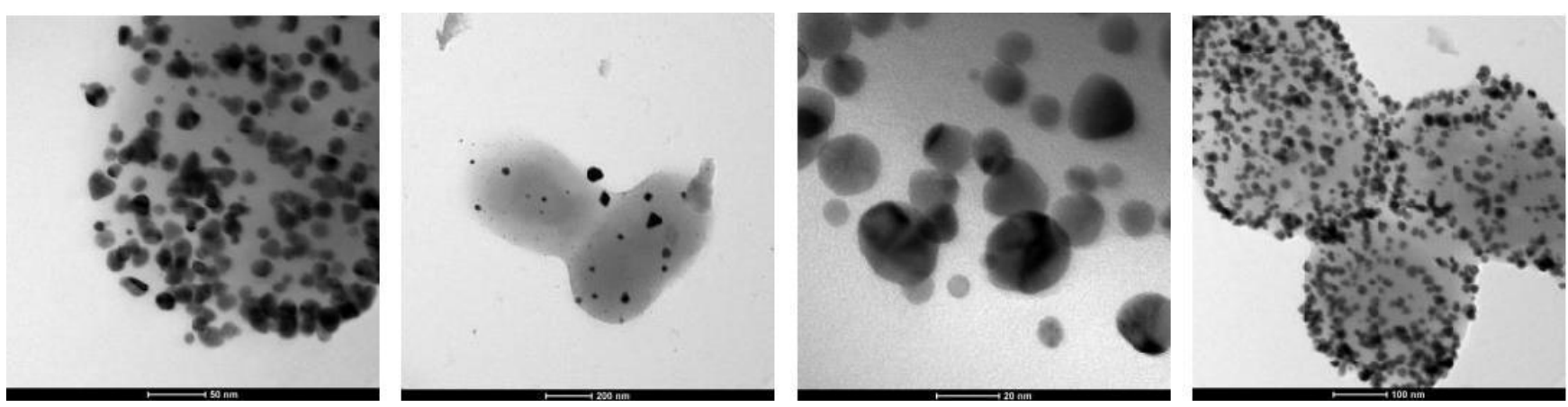

Figure 3: Morphology of AuNPs can be seen at $50^{\circ} \mathrm{C}$ in TEM analysis.

Authors PD is thankful to Department of Microbiology University of Pune and Prof BA Chopade for his guidance to carry out the research work. I also Acknowledge the assistance of Department of Physics, University of Pune for SEM, and TEM measurements and NCCS for their kin assistance in 16S r RNA sequencing

\section{References}

1. Charles AE, Mark SS (1982) Eight Year Persistence of Individual Differences in the Bacterial Flora of the Forehead. The Journal Of Investigative Dermatology 79: 51-52.

2. Charles AE, Mark SS (1978) Individual Differences in the bacterial Flora of the Skin of forehead: Pepetococcus Saccharyolytius. J of inestigative Dermatology 71: 152-153.

3. Charles EA (1974) Persisent individual Differences in the Bacterial Flora of Skin of Forehead: Numbers of Propenibacteria. The Journal of Investigative Dermatology 64: 42-46.

4. Evans CA, Stevens RJ (1976) Differencal Quantitation of surface and subsurface Bacteria of normal skin by the combined use of Cotton swab and the scrub methods. J Cli Microbiol 3: 576-581.

5. Evans CA, Stevens RJ (1978) Isolation and Identification of pepetococcus saccharolyticus from human skin. J Cli Microbiol 7: 261-264.

6. Ehrhardt P, Johanna M, Jens-Michael J (2008) The Skin: As Indespensible Barrier. Experimental Dermatology 17: 1063-1072.

7. Korting HC, Greiner K, Hubner K (1991) Change in $\mathrm{pH}$ and resident Flora by Washing By Synthetic Detergent preparation At pH 5.5 and 8.5.

8. James J L, McGiley J, Mills OH, Kligman AM (1975) Age- Related changes in The Resident Bacterial Flora of The Human Face. The Journal of Investigative Dermatology 65: 379-381.
9. Katarina C, Bryan AS, George JM (2001) Skin Microflora and Bacterial Infections of the Skin, Journal of Investigative Dermatology Symposium Proceedings 6: 170-174.

10. Elsner P (2006) Antimicrobial and the Skin Physiological and Pathological Flora.

11. Zhan G, Tseng C, Pei Z, Blasier MJ (2006) Molecular analysis of human forearm superficial skin bacterial biota. CrossMark 104: 2927-2932.

12. Grice A, JuliaAS (2011) The skin microbiome. Nat Rev Microbiol 9: 244-253.

13. Grice EA, Kong HH, Conlan S, Deming CB, Davis J, et al. (2009) Topographical and temporal diversity of the human skin microbiome. Science 324: 1190-1192.

14. Costello EK, Lauber CL, Hamady M, Fierer N, Gordon IJ, et al. (2009) Bacterial community variation in human body habitats across space and time. Science 326: 1694-1697.

15. Schmid G (1992) Large clusters and colloids. Metals in the embryonic state. Chem Rev 92: 1709-1727. 